\title{
SEDIAAN RAJALOM (RAMUAN JAMU LOMBOK) TERHADAP KADAR ASAM URAT PLASMA DAN GAMBARAN HISTOPATOLOGI AORTA RATTUS NOVERGICUS
}

\section{RAJALOM (Herb Herbal Lombok) Levels of Plasma Gout and Picture Histopathology Aortic Rattus Novergicus}

\author{
Maruni Wiwin Diarti, Rohmi, Yunan Jiwintarum \\ Poltekkes Kemenkes Mataram \\ (Email: maruniwiwindiarti@yahoo.com)
}

\begin{abstract}
ABSTRAK
Hiperurisemia penyebab radang sendi memerlukan penatalaksanaan pengobatan menggunakan bahan-bahan alam. Tujuan penelitian ini untuk mengkaji aktivitas ramuan khas Lombok RAJALOM terhadap kadar asam urat pada plasma dan urin serta mempengaruhi gambaran histopatologi aorta pada hewan coba Rattus novergicus dengan hiperuricema diinduksi diet tinggi kolesterol dan purin. Penelitian ini menggunakan hewan coba Rattus norvegicus yang diinduksi dengan diet tinggi purin dan koleterol dikombinasi potasium oksanat IP $42 \mathrm{mg} / 200 \mathrm{kkBB}$ tikus. Tikus putih dibagi menjadi 8 kelompok. Tikus putih hiperurecemia diberikan perlakuan pemberian aquades per sonde untuk kelompok kontrol negatif, alopurinol 1,8 mg/200gram BB Tikus untuk kelompok kontrol positif dan kelompok perlakuan diberikan ramuan khas Lombok RAJALOM. Pada akhir perlakuan diambil sampel darah, urin dan aorta untuk pemeriksaan kadar asam urat plasma, kadar asam urat urin dan gambaran histopatologi aorta. Hasil penelitian pemberian ramuan jamu dari Lombok RAJALOM selama 7 dan 14 hari mampu menurunkan kadar asam urat plasma hewan coba dengan rentang antara dan 45,7 \%- 77,27 \%, sedangkan pada kelompok kontrol positif / Allopurinol mampu menurunkan sampai dengan $86 \%$ pada hari ke 14. Tidak terdapat hubungan yang signifikan antara kelompok perlakuan terhadap kadar asam urat plasma hewan coba pada hari ke 7 dan hari ke 14.Tidak terdapat perbedaan yang signifikan antara kadar asam urat sebelum perlakuan dengan sesuadah perlakuan pada semua kelompok penelitian. Pemberian induksi dengan pakan tinggi lemak/purin selama 3 minggu pada hewan coba tikus (Rattus Novergicus) tidak menimbulkan terbentuknya plak aterosklerosis. Kesimpulan pemberian ramuan jamu dari Lombok RAJALOM selama 7 dan 14 hari mampu menurunkan kadar asam urat plasma hewan.
\end{abstract}

Kata Kunci: Aorta; RAJALOM; Kadar Asam Urat; Plasma; Urine; Rattus novergicus

\begin{abstract}
Hyperuricemia that causes arthritis requires treatment management using natural ingredients. The purpose of this study was to examine the activity of a typical Lombok herb RAJALOM on uric acid levels in plasma and urine and to influence the histopathological features of the aorta in Rattus novergicus experimental animals with hyperuricema induced by a diet high in cholesterol and purines. This study used experimental animals Rattus norvegicus induced by a diet high in purine and choleterol combined with potassium oxanate IP $42 \mathrm{mg} / 200 \mathrm{kkBW}$ rats. White rats were divided into 8 groups. Hyperurecemic white rats were treated with distilled water per sonde for the negatif control group, allopurinol $1.8 \mathrm{mg} / 200 \mathrm{gram}$ $B W$ Rats for the positive control group and the treatment group given a typical Lombok herb RAJALOM. At the end of the treatment, samples of blood, urine and aorta were taken for examination of plasma uric acid levels, uric acid levels and aortic histopathology. The results of this study were that giving herbs from Lombok RAJALOM for 7 and 14 days was able to reduce uric acid levels in experimental animals with a range between and $45.7 \%-77.27 \%$, while in the positive control group / Allopurinol was able to reduce up to $86 \%$ on the day. 14. There was no significant relationship between the treatment groups on plasma uric acid levels of experimental animals on day 7 and day 14. There was no significant difference between uric acid levels before treatment and according to treatment in all study groups. The induction of high fat / purine feed for 3 weeks in experimental mice (Rattus Novergicus) did not cause the formation of atherosclerotic plaques. The conclusion is that giving herbs from Lombok RAJALOM for 7 and 14 days was able to reduce uric acid levels in animal plasma.
\end{abstract}

\section{Keywords: Aorta; RAJALOM; Uric Acid Levels; Plasma; Urine; Rattus norvecicus}

https://doi.org/10.33860/jik.v14i2.222

(C) 2020 by the authors. Submitted for possible open access publication under the terms and conditions of the Creative Commons Attribution (CC BY SA) license (https://creativecommons.org/licenses/by-sa/4.0/). 


\section{PENDAHULUAN}

Indonesia merupakan negara yang memiliki keanekaragaman etnobotani (tanaman obat) yang dimiliki. Indonesia merupakan negara dengan biodiversitas tumbuhan terbesar kedua di dunia sehingga tersimpan potensi tanaman obat yang besar dan sampai saat ini belum tergali dengan maksimal. Potensi tersebut sangat besar untuk menjamin kesehatan dan kesejahteraan masyarakat apabila dimanfaatkan dengan baik $^{(1)}$. Banyak tantangan yang dihadapi dalam pengembangan jamu adalah belum terintegrasinya obat tradisional seperti belum adanya pengakuan dari profesi tenaga kesehatan (dokter, dokter gigi) bahwa jamu aman (tidak toksik), berdariiat (efikasi), dan mutunya terjamin (standar). Untuk memperoleh pengakuan itu harus dilakukan penelitian untuk memberikan bukti-bukti ilmiah yang mendukung bukti empiris yang telah diakui secara turun-temurun. Untuk menjawab tantangan tersebut, Pemerintah menyusun Grand Strategy Pengembangan Jamu antara lain melalui meningkatkan akses terhadap jamu yang bermutu, aman, dan berkhasiat. Salah satu tahapannya adalah mendukung penelitian terkait pengembangan obat tradisional $^{(1)}$. Pemerintah juga telah melakukan upaya pendokumentasian ramuanramuan yang berasal dari berbagai suku di Indonesia.

Salah satu ramuan yang telah didokumentasikan adalah ramuan dari lombok yang terdiri dari daun salam (Syzygium olyanthum), akar alang-alang (Imperara cylindrica), pegagang (Cantella asiatica) dan sambiloto (Adrographis paniculata). Ramuan ini merupakan ramuan untuk menurunkan kadar kolesterol ${ }^{(2)}$. Namun dari hasil literatur rewiew oleh didapatkan kandungan senyawa yang terdapat dalam bahan ramuan dapat menurunkan kadar asam urat, sehingga peneliti ingin membuktikan manfaat lain dari ramuan ini.

Pemilihan ramuan dan efek antihiperurecemia didasarkan pada, makin meningkatnya jumlah penderita hiperuricemia dan dampak hiperuricemia yang luas pada berbagai sistim organ, serta memberikan bukti ilmiah terhadap manfaat lain dari ramuan ini sehingga dapat dimanfaatkan secara lebih luas dan rasional, dan dilanjutkan dalam suatu penelitian saintifikasi jamu melalui penelitian berbasis pelayanan kesehatan.

Hiperuricemia adalah suatu kelainan metabolisme yang ditandai peningkatan kadar asam urat. Asam urat merupakan produk akhir dari metabolisme purin. Kadar normal asam urat pada manusia berkisar $7 \mathrm{mg} / \mathrm{dL}$ pada lakilaki dan $6 \mathrm{mg} / \mathrm{dL}$ pada perempuan. Pengingkatan kadar asam urat (Hiperuricemia), dapat disebabkan oleh salah satu atau lebih dari faktor-faktor berikut ini, yaitu peningkatan asupan purin, peningkatan aktivitas xantin oksdase sehingga produksi asam urat meningkat, dan penurunan ekskresi asam urat melalaui ginjal $^{(3)}$. Prevalensi hiperuricemia yang meningkat pesat di seluruh dunia dalam beberapa dekade terakhir. Hiperuricemia diketahui menjadi penyebab radang sendi, yang disebut dengan gout artritis. Selain itu, hiperuricemia juga telah telah dibuktikan memiliki dampak negatif pada kardiovaskuler, seperti Ateroskelrosis, hipertensi, penyakit jantung koroner dan gagal ginjal, serta dihubungkan juga dengan sindroma metabolik ${ }^{(3)}$.

Penatalaksanaan hyperuricemia dengan tepat, tidak hanya menurunkan keluhan nyeri sendi pada penderita gout artritis, mencegah serangan berulang pada penderita gout artritis, namun juga dapat mencegah terjadinya komplikasi pada sendi dan sistem kardiovaskuler dan ginjal. Penatalaksanaan hiperuricemia secara secara farmakologi dengan obat modern menggunakan beberapa golongan obat. Berdasarkan mekanisme yaitu $^{(4)}$ : Mengurangi aktivitas xantin oksidase. Xantin oksidase adalah suatu enzim yang memetabolismes purin menjadi asam urat. Penghambatan xantin oksidase dapat menurunkan produksi asam urat. Obat ini contohnya adalah Allopurinol. Meningkatkan ekskresi atau pembuangan asam urat melalui urin. Contoh sediaan obat ini adalah probenesid dan sulfinpyrazone. Obat-obat yang lain yang digunakan pada penderita hiperuricemia dengan manifestasi penyakit gout artritis bersifat mengurangi gejala, seperti sediaan analgetik-antiinflamasi golongan non steroid, steroid dan kolkisin ${ }^{(4)}$.

Beberapa senyawa yang terkandung dalam bahan alam telah dibuktikan secara invitro dan in vivo pada hewan coba mampu menurunkan kadar asam urat dengan menghambat xantin oksidase dan atau meningkatkan ekskresi asam urat. 
Pegagang (Cantella asiatica) mengandung senyawa antara lain alkaloid, saponin, steroid, terpenoid. Alkaloid dalam pegagang didindikasikan mampu menghambat xantin oksidase (Sugianto). Daun salam (Syzygium polyanthum) mengandung senyawa seperti tanin, flavonoid, lakton, saponin, steroid, triterpenoid, eugenol, vitamin $\mathrm{C}, \mathrm{A}$, tiamin, niacin, riboflavin, B12, dan asam folat $^{(5)}$. Kandungan dalam daun salam terbukti mampu menurunkan kadar asam urat yang diinduksi potasium oksanat (Siaga, dkk, 2014).

Daun sambiloto mengandung antara lain flavonoid turunan flavon yaitu hidroksi flavon $^{(6)}$. Flavonoid juga telah dibuktikan mampu menghambat xantin oksidase ${ }^{(7)}$. Ramuan jamu khas lombok yang dalam penelitian ini disebut RAJALOM ini terdiri atas 10 gram daun salam, 10 gram akar alangalang, 10 gram pegagang, dan 10 gram sambiloto yang dimasak dengan dua gelas air menjadi 3/4 gelas dan diminum 1 kali sehari sebelum tidur malam. Berdasarkan studi literatur sebagaimana yang disebutkan sebelumnya, bahan-bahan ini mengandung senyawa yang telah dibuktikan mampu menurunkan kadar asam urat. Namun, efek penurunan terhadap asam urat dan kelainan pada kardiovaskuler minimal pada Hewan coba belum tersedia data. Oleh karena itu, pada penelitian ini, akan menilai efek dari bahanbahan jamu dari Lombok ini yang dibuat dalam kombinasi satu ramuan menggunakan dosis sesuai menurut Barta dalam sediaan obat sebagai antihiperuricemia.

\section{METODE PENELITIAN}

Penelitian ini adalah penelitian quasi eksperimental dengan desain time series studi. Penelitian ini menggunakan hewan coba Rattus norvegicus yang diinduksi dengan diet tinggi purin dan koleterol dikombinasi potasium oksanat IP $42 \mathrm{mg} / 200 \mathrm{kkBB}$ tikus. Tikus putih dibagi menjadi 8 kelompok, yaitu 2 kelompok kontrol negatif (K1\&K2), 2 kelompok kontrol positif (A1\&A2), 4 kelompok perlakuan ramuan (R1, R2, R2, R3, R4). Tikus putih hiperurecemia diberikan perlakuan pemberian aquades per sonde untuk kelompok kontrol negatif, Alopurinol 1,8 mg/200gram BB Tikus untuk kelompok kontrol positif dan kelompok perlakuan diberikan ramuan khas Lombok RAJALOM. Pada akhir perlakuan hari ke-8 (K1, A1, R1 dan R3) dan ke-15 (K2, A2, R2 dan R 4) diambil sampel darah, urin dan aorta untuk pemeriksaan kadar asam urat plasma, kadar asam urat urin dan gambaran histopatologi aorta. Populasi penelitian ini adalah tikus putih jantan (Rattus norvegicus) yang sehat fisik berumur 2-3 bulan dengan berat 250-300gram.

Sampel penelitian ini adalah sebagian tikus putih (Rattus norvegicus) yang memenuhi kriteria inklusi dan eksklusi. Kriteria inklusi: Starin wistar, jantan, sehat, berusia 2-3 bulan dengan berat badan 250300gram. Menjadi hieruricemia dengan induksi diet tinggi purin dan lemak dikombinasi potasioum oksanat dimana kadar asam urat $\geq 3,5 \mathrm{mg} / \mathrm{dl}$. Kriteria eksklusi: Tikus tampak sakit, Tikus Mati saat intervensi dilakukan. Besar sampel (unit replikasi) dihitung berdasarkan rumus besar sampel eksperimental dari Federer ditambah dengan faktor koreksi sebesar $25 \%$, sehingga total besar sampel yang akan digunakan adalah 30 ekor tikus. Teknik Pengambilan sampel menggunakan NonRandom Purposive Sampling. Variabel bebas adalah dosis rebusan/ekstrak air ramuan jamu khas Lombok RAJALOM. Variabel terikat adalah kadar asam urat plasma dan gambaran histopatologi aorta.

\section{Pengelompokkan Sampel:}

Kelompok hewan coba pada dibagi secara acak menjadi 8 kelompok, meliputi:

a. Kelompok K1: Kelompok tikus yang diet tinggi purin dan kolesterol dikombinasi potasium oksanat IP $42 \mathrm{mg} / 200 \mathrm{kkBB}$ tikus diberikan akuades maksimal $0,5 \mathrm{ml} / \mathrm{hari}$ secara oral selama 7 hari sebagai kontrol negatif dan diterminasi pada hari ke-8.

b. Kelompok K2: Kelompok tikus yang diet tinggi purin dan kolesterol dikombinasi potasium oksanat IP $42 \mathrm{mg} / 200 \mathrm{kkBB}$ tikus diberikan akuades maksimal $0,5 \mathrm{ml} / \mathrm{hari}$ secara oral selama 14 hari sebagai kontrol negatif dan diterminasi pada hari ke-15.

c. Kelompok G1 (AL): Kelompok tikus yang yang diet tinggi purin dan kolesterol dikombinasi potasium oksanat IP 42 $\mathrm{mg} / 200 \mathrm{kkBB}$ tikus dan diberikan Allopurinoloral sebanyak $1,8 \mathrm{mg} / 200 \mathrm{gram}$ $\mathrm{BB}$ tikus/hari dalam $0,5 \mathrm{ml}$ akuades selama 7 hari sebagai kontrol positif dan diterminasi pada hari ke-8.

d. Kelompok G2 (AL): Kelompok tikus yang yang diet tinggi purin dan kolesterol 
dikombinasi potasium oksanat IP 42 $\mathrm{mg} / 200$ kkBB tikus dan diberikan Allopurinoloral sebanyak 1,8 mg/ 200gram BB tikus/hari dalam $0,5 \mathrm{ml}$ akuadesselama 14 hari sebagai kontrol positif dan diterminasi pada hari ke-15.

e. Kelompok R1 (A1): Kelompok tikus yang yang diet tinggi purin dan kolesterol dikombinasi potasium oksanat IP 42 $\mathrm{mg} / 200 \mathrm{kkBB}$ tikus dan diberikan rebusan / ekstrak air ramuan jamu RAJALOM sesuai dosis batra pada manusia yang dikonversi dosis hewan coba (0.018) satu kali sehari secara oral selama 7 hari sebagai kelompok perlakuan dan diterminasi pada hari ke-8.

f. Kelompok R2 (A2): Kelompok tikus yang yang diet tinggi purin dan kolesterol dikombinasi potasium oksanat IP 42 $\mathrm{mg} / 200 \mathrm{kkBB}$ tikus dan diberikan rebusan / ekstrak air ramuan jamu RAJALOM sesuai dosis batra pada manusia yang dikonversi dosis hewan coba (0.018) satu kali sehari secara oral selama 14 hari sebagai kelompok perlakuan dan diterminasi pada hari ke-15.

g. Kelompok R3 (B1): Kelompok tikus yang yang diet tinggi purin dan kolesterol dikombinasi potasium oksanat IP 42 $\mathrm{mg} / 200 \mathrm{kkBB}$ tikus dan diberikan rebusan / ekstrak air ramuan jamu RAJALOM 2 kali dosis batra pada manusia yang dikonversi dosis hewan coba (0.018) satu kali sehari secara oral selama 7 hari sebagai kelompok perlakuan dan diterminasi pada hari ke-8.

h. Kelompok R4 (B2): Kelompok tikus yang yang diet tinggi purin dan kolesterol dikombinasi potasium oksanat IP 42 $\mathrm{mg} / 200 \mathrm{kkBB}$ tikus dan diberikan rebusan / ekstrak air ramuan jamu RAJALOM dua dosis batra pada manusia yang dikonversi dosis hewan coba (0.018) satu kali sehari secara oral selama 14 hari sebagai kelompok perlakuan dan diterminasi pada hari ke-15.

i. Kelompok R5 (C1): Kelompok tikus yang yang diet tinggi purin dan kolesterol dikombinasi potasium oksanat IP 42 $\mathrm{mg} / 200 \mathrm{kkBB}$ tikus dan diberikan rebusan / ekstrak air ramuan jamu RAJALOM 3 kali dosis batra pada manusia yang dikonversi dosis hewan coba (0.018) satu kali sehari secara oral selama 7 hari sebagai kelompok perlakuan dan diterminasi pada hari ke-8.

j. Kelompok R6 (C2): Kelompok tikus yang yang diet tinggi purin dan kolesterol dikombinasi potasium oksanat IP 42 $\mathrm{mg} / 200 \mathrm{kkBB}$ tikus dan diberikan rebusan / ekstrak air ramuan jamu RAJALOM 3 dosis batra pada manusia yang dikonversi dosis hewan coba (0.018) satu kali sehari secara oral selama 14 hari sebagai kelompok perlakuan dan diterminasi pada hari ke-15.

\section{Cara Kerja Penelitian:}

a Pembuatan rebusan ramuan jamu khas Lombok RAJALOM:yang terdiri dari 10 gram daun salam, 10 gram akar alang-lang, 10 gram pegagang, dan 10 gram sambiloto yang dimasak dengan dua gelas air menjadi $3 / 4$ gelas (1 kali Dosis). Penyediaan ramuan untuk seluruh perlakuan akan dilakukan 1 kali pada tahap persiapan penelitian. Semua bahan ramuan yang dibutuhkan sesuai dengan dosis kelompok, dimasak dengan volume air yang sesuai panduan Batra sehingga menjadi $3 / 4$ volume semula. Hasilnya didinginkan dan dilakukan freeze drying sehingga terbentuk sedian berbentuk bubuk kering. Proses pembuatan ramuan dilakukan pada laboratorium Farmakologi Fakultas Kedokteran Universitas Mataram.

b Nekropsi dan pengambilan sampel: Subyek dikurbankan dengan ether dosis letal, selanjutnya sampel darah diambil secara intrakardiak. Rongga abdomen dibuka untuk mengambil organ. direndam dalam etanol $70 \%$, setelah itu dicuci dengan air mengalir. Aorta kemudian diwarnai dengan pewarna SUDAN IV dan direndam dalam formalin $10 \%$ untuk di buat sediaan PA. Pembuatan sediaan Histopatologi, pemeriksaan dan pembacaan dilakukan di Laboratorium Patologi Anatomi RSI Siti Hajar Mataram.

c Pemeriksaan kadar asam urat plasma dan urine: Darah yang dipisahkan dan diambil plasmanya, pemeriksaan kadar asam urat menggunakan fotometer dan reagen asam urat dari Humman. Metode yang digunakan: Uracase-PAP Method.

\section{Analisa Data}

Data yang dikumpulkan dianalisa statistik menggunakan Anova jika data berdistribusi normal dan homogen atau Kruskal-Wallis jika data tidak berdistribusi normal dan homoge.

\section{Kelayakan etik Penelitian}

Kelayakan etik Penelitian dari Komisi etik penelitian kesehatan Universitas mataram Nomor 58/UN18.8/ETIK/2016 tanggal 27 Juni 2016. 


\section{HASIL}

Tabel di 1 dan 2 menunjukkan adanya penurunan kadar asam urat plasma pada masing-masing kelompok perlakuan dan kontrol Allopurinol pasca induksi dengan makanan tinggi purin/sebelum diberikan perlakuan dengan setelah perlakuan selama 7 dan 14 hari. Kadar Asam urat tetap tinggi pada kelompok kontrol negatif yang hanya diberikan pakan standart dan aquadest. Data pada tabel 3 menunjukkan persentase penurunan kadar asam urat plasma pada hewan coba setelah perlakuan dibandingkan dengan sebelum perlakuan. Pada tabel di atas, terlihat bahwa persentase penurunan kadar asam urat plasma tertinggi diperoleh pada kelompok kontrol positif /Allopurinol, yaitu mencapai 89 $\%$, pasca pemberian selama 14 hari. Persentase penurunan kadar asam urat plasma terendah didapatkan pada kelompok dosis III, setelah pemerian perlakuan, yaitu rebusan jamu RAJALOM selama 14 hari. Persentase penurunan kadar asam urat pada kelompok lain, berkisar antara 64,00 \% sampai dengan $77,27 \%$. Kondisi ini menunjukkan kecenderungan potensi jamu RAJALOM dalam menurunkan kadar asam urat plasma.

Analisis statistik untuk mengetahui pengaruh RAJALOM terhadap kadar asam urat dalam plasma, berdasarkan hasil uji normalitas, didapatkan sebaran data tidak normal, sehingga uji hipotesis menggunakan uji non parametrik Kruskal Wallis. Hasil uji dapat dilihat pada tabel 4 .

Tabel 1. Rerata kadar asam urat plasma hewan coba sebelum perlakuan dan setelah perlakuan 7 hari

\begin{tabular}{|c|c|c|}
\hline \multirow[t]{2}{*}{ Kelompok } & \multicolumn{2}{|c|}{$\begin{array}{c}\text { Asam urat plasma } \\
\text { perlakuan selama } 7 \text { hari } \\
(\mathrm{mg} / \mathrm{dL})\end{array}$} \\
\hline & $\begin{array}{c}\text { Sebelum } \\
\text { perlakuan }\end{array}$ & $\begin{array}{c}\text { Setelah } \\
\text { perlakuan }\end{array}$ \\
\hline Kontrol Negatif & $4,95 \pm 0,071$ & $4,75 \pm 0,071$ \\
\hline Kontrol Allopurinol & $4,60 \pm 1,200$ & $1,60 \pm 0,458$ \\
\hline Dosis I & $9,30 \pm 6,255$ & $2,67 \pm 2,060$ \\
\hline Dosis II & $4,17 \pm 1,290$ & $1,50 \pm 0,566$ \\
\hline Dosis III & $5,87 \pm 3,075$ & $1,53 \pm 1,097$ \\
\hline
\end{tabular}

Sumber: Data Primer, 2017
Tabel 2. Rerata kadar asam urat plasma hewan coba sebelum perlakuan dan setelah perlakuan 14 hari

\begin{tabular}{lcc}
\hline \multirow{1}{*}{ Kelompok } & \multicolumn{2}{c}{$\begin{array}{c}\text { Asam urat plasma } \\
\text { perlakuan selama 14 } \\
\text { hari (mg/dL) }\end{array}$} \\
\cline { 2 - 3 } & $\begin{array}{c}\text { Sebelum } \\
\text { perlakuan }\end{array}$ & $\begin{array}{c}\text { Setelah } \\
\text { perlakuan }\end{array}$ \\
\hline Kontrol Negatif & $4,95 \pm 0,071$ & $4,85 \pm 0,071$ \\
Kontrol Allopurinol & $7,25 \pm 5,586$ & $0,80 \pm 0,283$ \\
Dosis I & $7,70 \pm 3,604$ & $1,75 \pm 0,778$ \\
Dosis II & $8,33 \pm 7,506$ & $1,95 \pm 0,919$ \\
Dosis III & $3,50 \pm 2,830$ & $1,9 \pm 0,141$ \\
\hline
\end{tabular}

Sumber: Data Primer, 2017

Tabel 3. Persentase Penurunan kadar asam urat plasma hewan coba pada kontrol Allopurinol dan perlakuan setelah perlakuan 7 dan 14

\begin{tabular}{lcc}
\hline \multirow{2}{*}{ Kelompok } & \multicolumn{2}{c}{$\begin{array}{c}\text { \% Penurunan Asam } \\
\text { Urat Plasma } \\
\text { Setelah Perlakuan }\end{array}$} \\
\cline { 2 - 3 } & $\begin{array}{c}\text { Setelah } \\
\text { hari ke 7 }\end{array}$ & $\begin{array}{c}\text { Setelah } \\
\text { hari ke 14 }\end{array}$ \\
\hline Kontrol Allopurinol & 65,22 & 89,00 \\
Dosis I & 71,33 & 77,27 \\
Dosis II & 64,00 & 76,60 \\
Dosis III & 73,86 & 45,70 \\
\hline
\end{tabular}

Sumber: Data Primer, 2017

Tabel 4. Hasil Uji Hipotesis dengan Kruskal Wallis

\begin{tabular}{lr}
\hline \multicolumn{1}{c}{ Kelompok (Hari) } & Asymp. Sig. \\
\hline Setelah hari 7 & 0,693 \\
Setelah hari ke 14 & 0,244 \\
\hline
\end{tabular}

Sumber: Data Primer, 2017

Hasil Uji hipotesis menunjukkan bahwa tidak ada pengaruh yang signifikan perlakuan, baik Allopurinol maupun jamu RAJALOM selama 7 dan 14 hari dalam menurunkan kadar asam urat plasma pada hewan coba. Namun secara persentase terdapat penurunan yang sangat berarti dari pemberian RAJALOM. Untuk melihat pengaruhnya pada masingmasing kelompok, maka dilajutkan dengan uji Wilcoxon.

Tabel 5. Hasil Uji Hipotesis Wilcoxon

\begin{tabular}{lcc}
\hline Kelompok & $\begin{array}{c}\text { Sebelum } \\
\text { perlakuan } \\
\text { dan } \\
\text { setelah 7 } \\
\text { hari } \\
\text { pelakuan }\end{array}$ & $\begin{array}{c}\text { Sebelum } \\
\text { perlakuan } \\
\text { dan } \\
\text { setelah 14 } \\
\text { hari } \\
\text { pelakuan }\end{array}$ \\
\hline Kontrol alopurinol & 0.109 & 0.180 \\
Dosis I & 0.109 & 0.180 \\
Dosis II & 0.180 & 0.180 \\
Dosis III & 0.109 & 0.180 \\
\hline
\end{tabular}

Sumber: Data Primer, 2017 
Hasil Uji Wilcoxon sebagaimana dijabarkan dalam tabel 5, tidak ada perbedaan yang signifikan kadar asam urat plasma sebelum dan setelah perlakuan pada masingmasing kelompok.

\section{Gambaran Histopatologi Aorta}

Gambaran Makroskopis aorta hewan coba pada semua kelompok perlakuan setelah perlakuan 7 dan 14 hari, tidak ditemukan plak ateroskelrosis. Hasil pemeriksaan mikroskopis, juga tidak terdapat plak aterosklerosis dan sel busa pada semua sediaan aorta hewan coba setelah perlakuan 7 dan 14 hari. Adapun gambar dari hasil Histopatologi aorta dapat dilihat pada gambar 1 s.d 4 .

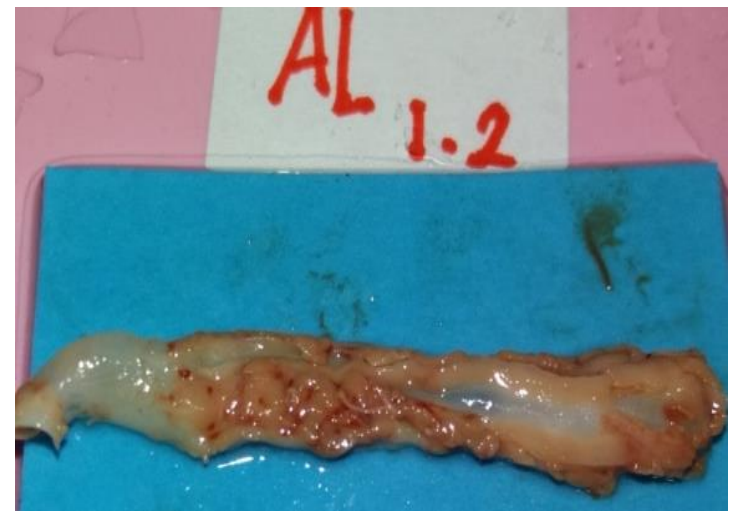

Sumber: Data Primer, 2017

Gambar 1. Potongan Histopatologi Aorta yang diberikan Alopurinol

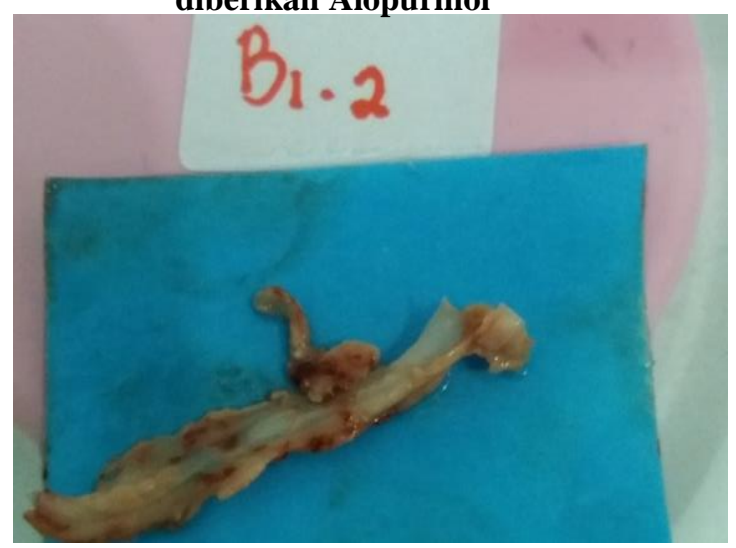

Sumber: Data primer 2020)

Gambar 2. Potongan Histopatologi Aorta yang diberikan RAJALOM Dosis III

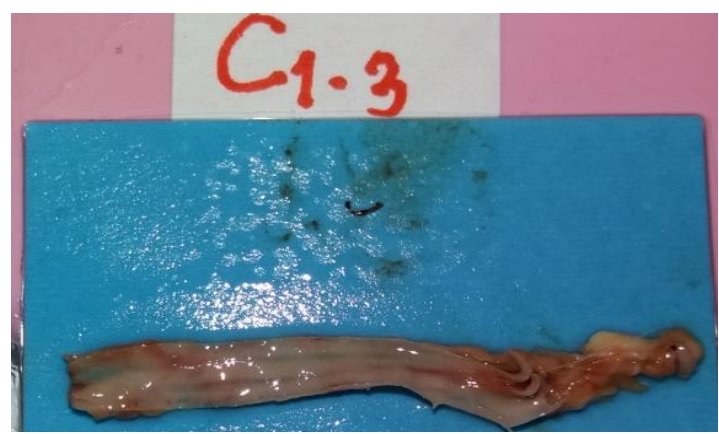

Sumber: Data Primer, 2017

Gambar 3. Potongan Histopatologi Aorta yang diberikan RAJALOM Dosis II

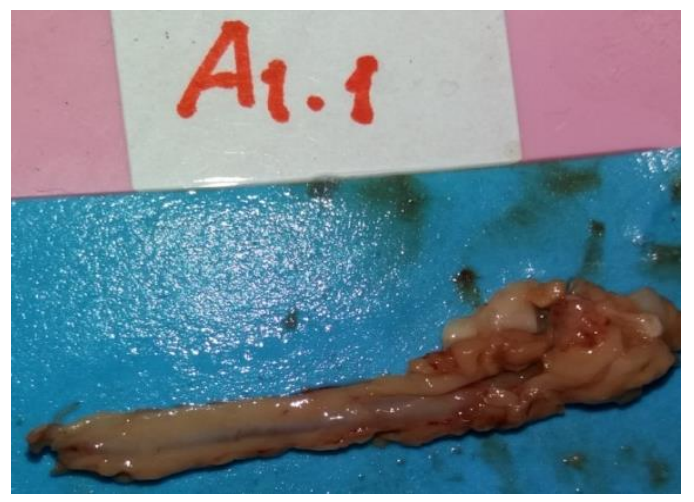

Sumber: Data Primer, 2017

Gambar 4. Potongan Histopatologi Aorta yang diberikan RAJALOM Dosis I

\section{PEMBAHASAN}

Potensi jamu/ramuan RAJALOM dalam menurunkan kadar asam urat plasma pada hewan coba.

Penelitian ini ingin membuktikan potensi jamu RAJALOM yang komposisinya terdiri atas daun salam, daun sambiloto, pegagang dan akar alang-alang dalam menurunkan kadar asam urat dan mencegah terjadinya komplikasi aterosklerosis pada hewan coba. Pada penelitian ini juga dilakukan eksplorasi dosis ramuan, untuk mencari dosis yang lebih efektif.

Pada penelitian ini, induksi hiperuricemia yang awalnya akan menggunakan kombinasi diet tinggi lemak/purin dan pottasium oksanat IP dimodifikasi menjadi hanya pemberian diet tinggi lemak/purin saja. Diet tinggi purin dengan komposisi pakan standar, tepung melinjo, telur puyuh, lemak sapi dan margarine, selama 3 minggu, terbukti mampu meningkatkan kadar asam urat plasma hewan coba. Penelitian lain juga membuktikan, 
pemberian pakan tinggi lipid, mampu meningkatkan kadar asam urat plamsa, seperti pada penelitian oleh Restusari, dkk (2014), dimana pemerian pakan berupa homogenate hati sapi 3\% BB selama 21 hari, mampu meningkatkan kadar asam urat plasma tikus.

Hasil penelitian ini menunjukkan potensi jamu/ramuan RAJALOM pada berbagai dosis dan lama pemberian 7 dan 14 hari dalam mampu menurunkan kadar asam urat plasma pada hewan coba. Pada dosis I (Batra) yang merupakan dosis digunakan secara turun -temurun, penurunan kadar asam urat setelah 7 dan 14 hari pemberian, mampu menurunkan $6,63 \mathrm{mg} / \mathrm{dl}$ dan $5,95 \mathrm{mg} / \mathrm{dl}$. Jika dibandingkan dengan kadar asam urat plasma sebelum pemberian jamu, persentase penurunnya mencapai $71,33 \%$ dan $77,27 \%$. Pada dosis II, dimana dosis ditingkatkan menjadi 2 kali dosis Batra, rerata penurunan kadar asam urat plasma $2,67 \mathrm{mg} / \mathrm{dl}$ dan 6,38 $\mathrm{mg} / \mathrm{dl}$ atau sebesar $64 \%$ dan $76,60 \%$ jika dibandingkan kadar asam urat sebelum perlakuan, pada pemberian 7 dan 14 ramuan. Dosis III, yaitu dengan konsentrasi bahan 3 kali dosis Batra, didapatkan persentase penurunan lebih tinggi setelah pemberian ramuan 7 hari, dibandingan dengan setelah 14 hari, yaitu $73,86 \%$ dan $45,7 \%$. Persentase penurunan kadar asam urat plasma hari ke 7 , lebih tinggi pada kelompok ramuan dibandingkan dengan kelompok kontrol Allopurinol, namun pasca hari 14, penurunan kelompok Allopurinol mencapai $86 \%$.

Uji Hipotesis Kruskall Wallis, tidak terbukti adanya hubungan yang signifikan antara pemberian Allopurinol dan peningkatan dosis ramuan dengan kadar asam urat plasma hewan coba, baik setelah pemberian 7 hari, maupun setelah 14 hari. Pada uji dengan LSD, tidak terdapat perbedaan kadar antara kelompok kontrol positif/Allopurinol dengan semua kelompok ramuan, dan antara sesama kelompok ramuan, baik sebelum pemberian perlakuan, maupun setelah 7 dan 14 hari perlakuan. Hal ini menunjukkan bahwa efek ramuan RAJALOM, setara dengan Allopurinol yang merupakan obat standar dalam penatalaksanaan hiperurisemia.

\section{Kandungan masing - masing ramuan RAJALOM.}

Ramuan RAJALOM mempunyai bahan dasar yang telah diteliti secara terpisah mampu mengandung senyawa yang mampu menurunkan kadar asam urat. Daun salam (Syzygium polyanthum) mengandung senyawa seperti tanin, flavonoid, lakton, saponin, steroid, triterpenoid, eugenol, vitamin $\mathrm{C}, \mathrm{A}$, tiamin, niacin, riboflavin, B12, dan asam folat ${ }^{(5)}$. Akar alang-alang (Imperata cylindrica) mengandung tannin, flavonoid, saponin, alkaloid dan steroid (11-13). Pegagang (Cantella asiatica) mengandung senyawa antara lain alkaloid, saponin, steroid, terpenoid. Alkaloid dalam pegagang diindikasikan mampu menghambat xantin oksidase $^{(8)}$. Daun sambiloto mengandung antara lain flavonoid turunan flavon yaitu hidroksi flavon ${ }^{(6)}$.

Kandungan dalam bahan dasar RAJALOM salah satunya adalah kelompok flavonoid. Kemampuan senyawa tersebut dalam menurunkan asam urat adalah dengan mekanisme hambatan terhadap aktivitas xantin oksidase pada basa purin sehingga akan menurunkan produksi asam urat. Hal ini sesuai dengan pendapat Cos et.al tahun 1989 bahwa dari harga IC 50 flavonoid menyatakan bahwa $50 \%$ penghambatan xantin oksidase sama dengan $50 \%$ penurunan produksi asam urat. Jenis flavonoid yang berperan dalam mekanisme penghambatan enzim xantin oxidase adalah flavon dan flavonol ${ }^{(9)}$. Menurut Cos, et la (1998), kapasitas penghambatan xantin oksidase oleh flavolonid, terkait dengan strukturnya. Kelompok hidroxyl pada C-5 dan C-7 dan adanya ikatan ganda antara C-2 dan C-3, mempunyai kapasitas penghambtan xantin oksidase paling kuat. Flavon memperlihatkan kapasits penghambatan sedikit lebih tinggi dari flanonols.

Berdasarkan kapasitas penghambatan terhadap xantin oksidase dan efek superoxide scavengers, flavonoid dikelompokkan atas 6 kelompok. Kelompok A merupakan yang paling kuat. Quarcetin juga mampu menghambat xantin oksidase dengan kuat, dan masuk kategori A.Kadar total fenolik daun salam mencapai $614.70 \mathrm{mg}$ GAE/100 gram simplisia ${ }^{(10)}$. Flavonoid yang aman untuk dikonsumsi adalah sebesar 20-240 mg per hari. Rentang dosis ini tidak memberikan efek samping yang merugikan kesehatan ${ }^{(11)}$. Penelitian lain menemukan bahwa pemberian flavonoid jenis quercetin pada hewan coba tikus sebesar $2000 \mathrm{mg} / \mathrm{kgBB}$ per hari meningkatkan keparahan dari keganasan epitel 
tubular ginjal (12). Flavonoid merupakan senyawa yang mudah rusak akibat suhu. Flavonoid (fenol) memiliki suhu optimal $0^{\circ} \mathrm{C}$ $65^{\circ} \mathrm{C}^{(12)}$. Pada penelitian, ramuan dimasak pada suhu yang lebih $65^{\circ} \mathrm{C}$ dalam jangka waktu yang lama. Hal ini diduga berpengaruh terhadap hasil penelitian ini.

\section{KESIMPULAN DAN SARAN}

Pemberian Ramuan jamu dari Lombok RAJALOM selama 7 dan 14 hari mampu menurunkan kadar asam urat plasma hewan coba dengan rentang antara dan 45,7\%$77,27 \%$, sedangkan pada kelompok kontrol positif/Allopurinol mampu menurunkan sampai dengan $86 \%$ pada hari ke 14 . Tidak terdapat perbedaan yang signifikan antara kelompok perlakuan terhadap kadar asam urat plasma hewan coba pada hari ke 7 dan hari ke 14. Tidak terdapat perbedaan yang signifikan antara kadar asam urat plasma hewan coba sebelum perlakuan dengan sesudah perlakuan antara kelompok kontrol positif dengan kelompok perlakuan. Pemberian induksi dengan pakan tinggi lemak/purin selama 3 minggu pada hewan coba tikus (Rattus Novergicus) tidak menimbulkan terbentuknya plak aterosklerosis.

Perlu dilakukan uji kadar dan jenis flavonoid yang terdapat dalam ramuan khas Lombok RAJALOM pada berbagai jenis suhu. Perlu penelitian lebih lanjut mengenai uji Toksisitas dan uji klinik dari ramuan RAJALOM.

\section{UCAPAN TERIMA KASIH}

Terima kasih kepada Direktur Poltekkes Kemenkes Mataram, Kepala Laboratorium Farmakologi Universitas Mataram yang telah memfasilitasi pelaksanaan penelitian.

\section{DAFTAR PUSTAKA}

1. Purwadianto A. Jamu Menjadi Tuan Rumah Di Negeri Sendiri. Kementeri Kesehat [Internet]. 2010; Available from: http://www.depkes.go.id/article/print/1204/j amu-menjadi-tuan-rumah-di-negerisendiri.html

2. Badan Pegawas Obat dan Makanan.
Dokumentasi Ramuan Etnomedisin Obat Asli Indonesia, edisi Khusus. 2013.

3. Edwards NL. The role of hyperuricemia in vascular disorders. Curr Opin Rheumatol. 2009;21(2):132-7.

4. Brunton L. As bases farmacológicas da terapêutica de Goodman e Gilman. 11th ed. Porto Alegre: Mc. Graw Hill \& Co; 2010. 796-797 p.

5. Taufiqurrohman. Indonesian bay leaves as antidiabetic for type 2 diabetes mellitus. Majority. 2015;4(3):101-8.

6. Septianingsih U, Susanti H, Widyaningsih W. Penghambatan Aktivitas Xanthine Oxidase oleh Ekstrak Etanol Akar Sambiloto (Andrographis paniculata, Ness) Secara in Vitro. PHARMACIANA. 2012;2(2).

7. Nagao A, Seki M, Kobayashi H. Inhibition of xanthine oxidase by flavonoids. Biosci Biotechnol Biochem. 1999;63(10):178790.

8. Sugianto IS. Uji fitokimia ekstrak pegagan (Centella asiatica) dan buah sirsak (Annona muricata L.) serta potensinya sebagai inhibitor enzim xantin oksidase. Universitas Negeri Malang; 2013.

9. Cos $\mathrm{P}$, Ying L, Calomme $\mathrm{M}, \mathrm{Hu} \mathrm{JP}$, Cimanga K, Van Poel B, et al. Structureactivity relationship and classification of flavonoids as inhibitors of xanthine oxidase and superoxide scavengers. J Nat Prod. 1998;61(1):71-6.

10. Dewi TK. Isolasi, Uji Penghambatan Aktivitas Xantin Oksidase dan Identifikasi Senyawa Aktif dari fraksi n-Butanol pada ekstrak akar tanaman Acalypha indica Linn. Universitas Indonesia Jakarta; 2012.

11. Skibola CF, Smith MT. Potential health impacts of excessive flavonoid intake. Free Radic Biol Med [Internet]. 2000;29(34):375-83. Available from: http://dx.doi.org/10.1016/s08915849(00)00304-X

12. Harwood M, Danielewska-Nikiel B, Borzelleca JF, Flamm GW, Williams GM, Lines TC. A critical review of the data related to the safety of quercetin and lack of evidence of in vivo toxicity, including lack of genotoxic/carcinogenic properties. Food Chem Toxicol [Internet]. 2007;45(11):2179-205. Available from: http://dx.doi.org/10.1016/j.fct.2007.05.015 